\title{
DISABILITY AND REASONABLE ACCOMMODATION: $H M V$ SWEDEN COMMUNICATION 3/2011 (COMMITTEE ON THE RIGHTS OF PERSONS WITH DISABILITIES)
}

\author{
Ilze GrobBelaAR-Du Plessis $^{*} \&$ AnNelize Nienaber**
}

\author{
Key word: Disability
}

\section{INTRODUCTION}

The Convention on the Rights of Persons with Disabilities ${ }^{1}$ and the Optional Protocol to the CRPD ${ }^{2}$ were signed by South Africa on 30 March 2007 and ratified on 30 November 2007.' The CRPD is intended to 'promote and protect the rights and dignity of persons with disabilities' in order to 'redress ... the profound social disadvantage of persons with disabilities and promote their participation in the civil, political, economic, social and cultural spheres with equal opportunities, in both developing and developed countries ${ }^{4}$ and the Optional Protocol is aimed at facilitating the submission of individual complaints against State Parties relating to the CRPD.

* Senior Lecturer, Department of Public Law, Faculty of Law, University of Pretoria.

** Associate Professor, Department of Public Law, Faculty of Law, University of Pretoria.

1 Convention on the Rights of Persons with Disabilities (adopted 13 December 1966, entered into force 2 May 2008) UNGA/61/106 2515 UNTS 3 (CRPD). See generally R Kayess \& P French 'Out of Darkness into Light? Introducing the Convention on the Rights of Persons with Disabilities' (2008) 8 Human Rights LR; JE Lord \& MA Stein 'Assessing Economic, Social and Cultural Rights: The Convention on the Rights of Persons with Disabilities' in M Langford \& E Reidel (eds) Equality and Economic and Social Rights (2010) 4-5; A Lawson 'The UN Convention on the Rights of Persons with Disabilities and European Disability Law: A Catalyst for Cohesion?' in O Arnardottir \& G Quinn (eds) The United Nations Convention on the Rights of Persons with Disabilities European and Scandinavian Perspectives (2009) 320; C O'Cinneide 'Extracting Protection for the Rights of Persons with Disabilities from the Human Rights Framework Established Limits and New Possibilities' in G Quinn \& O Arnadottir (eds) The UN Convention on the Rights of Persons with Disabilities European and Scandinavian Perspectives (2009).

2 Optional Protocol to the Convention on the Rights of Persons with Disabilities (adopted 13 December 2006) UNGA /61/611 2515 UNTS 3 (Optional Protocol).

3 Note 1 above.

4 CRPD Preamble para y. See also M Schulze Understanding the UN Convention on the Rights of Persons with Disabilities A Handbook on the Human Rights of Persons with Disabilities (2009) $<$ http://www.makingitwork-crpd.org/resource-library/crpd>; G Quinn \& A Arnstein-Kerslake "Restoring the "Human" in Human Rights - Personhood and Doctrinal Innovation in the UN Disability Convention' in C Gearty \& C Douzinas (eds) The Cambridge Companion to Human Rights Law (2013).

5 CRPD art 1. 
On 3 November 2008, in terms of art 34 of the CRPD, a monitoring Committee on the Rights of Persons with Disabilities (CRPD Committee) was elected to monitor compliance of State Parties with their treaty obligations under the CRPD. ${ }^{6}$ The CRPD Committee is empowered to hear complaints related to violations of the CRPD that have been submitted by individuals, groups or by third parties. As HMv Sweden ${ }^{8}$ is the first instance in which the CRPD Committee resolved a communication brought against a state under the Optional Protocol to the CRPD, it is important to examine closely the issues raised in the communication, as well as deliberate upon the implications of the CRPD Committee's views for the rights of persons with disabilities in South Africa.

\section{FACTS}

HM, a Swedish national, suffers from a chronic connective tissue disorder called Ehlers-Danlos Syndrome (EDS) which has led to her being house-bound and bed-ridden, being unable to walk or stand, and even having difficulty sitting or lying down. ${ }^{9}$ At the point of submitting the communication, HM's disability had reached a stage where she no longer left her house and was no longer able to be transported to a hospital or rehabilitation care centre as these presented an increased risk of injury. ${ }^{10}$ The only rehabilitation feasible for someone in HM's situation is hydrotherapy; in HM's case, this would be possible only if she were to construct an indoor pool in her house. ${ }^{11}$

In December 2009, HM applied to the Örebo Local Housing Committee for planning permission for an extension of approximately 63 square metres to her house on her privately-owned land in order to build a hydrotherapy pool. The extension would to a large extent (approximately 45 square metres) be on land where building was not permitted. ${ }^{12}$ Because of this restriction on building, the Local Housing Committee rejected her application. HM subsequently appealed to a number of bodies, including to the Administrative Court of Appeal in Gothenburg. All her appeals were refused, as was her petition to the Supreme Administrative Court in Stockholm for leave to appeal the decision of the Administrative Court of Appeal. ${ }^{13}$

HM turned to the CRPD Committee and, invoking arts 1 to 5, 9 and 10, 14, $19,20,25,26$ and 28 of the CRPD in her communication, she alleged that the above facts constitute discrimination by the State Party as its administrative bodies and courts have failed to take cognisance of her rights to 'equal

CRPD, (note 1 above).

Ibid art 34.

$8 H M v$ Sweden Communication 3/2011, CRPD/C/7/D/3/2011 (19 April 2012). Also see F Mégret \& D Msipa 'Global Reasonable Accommodation: How the Convention on the Rights of Persons with Disabilities Changes the Way we think about Equality' in this Special Issue.

9 Ibid.

10 Ibid para 2.2.

11 Ibid.

12 Ibid para 2.3.

13 Ibid para 2.7. 
opportunity for rehabilitation and improved health'. ${ }^{14}$ She alleged that, while on the face neutrally applying the rules regarding planning permission, the State Party is in fact indirectly discriminating against her. HM further argued that the health, interest and well-being of a person with disability may be considered more important than the public interest of not allowing her application to build a hydrotherapy pool (which in any way would be on land which she owned, would not be visible from the street, and was with the consent of her neighbours). ${ }^{15}$ The CRPD Committee therefore had to consider whether HM's rights in terms of the CRPD had priority over the decision of the Local Housing Committee in terms of the Planning and Building Act (which protects the public interest). ${ }^{16}$

In its submission to the CRPD Committee, Sweden conceded that HM had exhausted domestic remedies, but maintained that her claim lacked substantiation and should be declared inadmissible pursuant to art 2(e) of the Optional Protocol. ${ }^{17}$ Regarding the merits of HM's communication, Sweden argued that a construction of 125 square metres would constitute a major departure from the development plan and was not possible under the Planning and Building Act. ${ }^{18}$ Instead, the State Party argued, HM should exercise her rights in terms of the Swedish Health and Medical Services Act, which entitles her to gain access to rehabilitation services via her local county council. ${ }^{19}$ The State Party argued, thus, that the laws applied to HM's case were not discriminatory and therefore not a violation of art 5 of the CRPD. ${ }^{20}$

In her response to the State Party's submissions, HM argued that the application of laws and regulations which appeared neutral on the surface constituted indirect unfair discrimination against her. ${ }^{21}$ She argued further that she had a rightful claim to equality with regard to quality of life as her individual interests strongly outweighed the interests of society at large. ${ }^{22}$

\section{DECISION}

The CRPD Committee found that the admissibility requirements of art 2(d) of the Optional Protocol had been met by $\mathrm{HM}^{23}$ While rejecting some of HM's allegations as being without substantiation and therefore also inadmissible, ${ }^{24}$

para 3.1.

15 Ibid paras 3.1-2.

16 Ibid para 3.2.

17 Ibid. Sweden further argued that the Committee does not have the authority to overturn a judgment by a Swedish court or a decision by a Swedish authority. Nor does it have the power to replace the domestic judgment or decision with a decision of its own. According to Sweden, the Committee can only conclude either that the circumstances of the case reveal a violation of the Convention or that there has been no such violation (see para 3.2).

$18 H M v$ Sweden (note 8 above) para 4.2.

19 Ibid paras 4.13-15.

20 Ibid para 4.15.

21 Ibid para 5.2.

22 Ibid para 5.4.

23 Ibid para 7.2.

24 Ibid para 7.4. 
the Committee found the rest of the violations claimed by HM to be admissible and proceeded to consider the merits of the communication.

The Committee observed, regarding the state's argument that it applies the laws regarding building permissions equally to all people, that 'a law which is applied in a neutral manner may have a discriminatory effect when the particular circumstances of the individuals to whom it is applied are not taken into consideration'. ${ }^{25}$ In other words, the Committee found that a state's failure to treat a person with disabilities differently when the situation warrants it, amounts to discrimination as the definition of discrimination on the basis of disability ${ }^{26}$ in terms of the Convention includes 'denial of reasonable accommodation, ${ }^{27}$ Reasonable accommodation is defined in art 2(4) of the CRPD as:

necessary and appropriate modification and adjustments not imposing a disproportionate or undue burden, where needed in a particular case, to ensure to persons with disabilities the enjoyment or exercise on an equal basis with others of all human rights and fundamental freedoms.

In view of the fact that the requested departure from the state's development plan would not impose a 'disproportionate or undue burden', the Committee further found that HM's right in terms of art 25 of the Convention, that of the enjoyment of the highest attainable standard of health without discrimination on the basis of disability, had been violated, as the refusal of a departure from the development plan in order to allow the building of a hydrotherapy pool was disproportionate and produced a discriminatory effect that adversely affected the author's access, as a person with disability, to the health care and rehabilitation required for her specific health condition. ${ }^{28}$ As a consequence, the Committee concluded that HM's rights under arts 5(1), $5(3), 25$, and Sweden's obligations under art 26 of the CRPD, read alone and in conjunction with arts 3(b), (d) and (e), and 4(1)(d) of the CRPD, had been violated. ${ }^{29}$ A further violation was found of art 19(b) of the Convention which guarantees that State Parties ensure that persons with disabilities have access 'to a range of in-home, residential and other community support services, including personal assistance necessary to support living and inclusion in the community, and to prevent isolation or segregation from the community. ${ }^{30}$ The Committee did not consider it necessary to address the author's claims under art 28 of the Convention, ${ }^{31}$ finding that the state had failed to fulfil its obligations under art 5(1), 5(3), 19(b), 25 and 26, read alone and in conjunction with arts 3(b), (d) and (e), and 4(1)(d) of the Convention. ${ }^{32}$

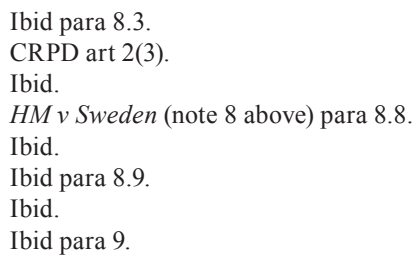


The Committee concluded by making a number of recommendations to the state. ${ }^{33}$ First, Sweden had to remedy its violation of HM's CRPD rights by reconsidering her application for a building permit for a hydrotherapy pool, taking into account the CRPD Committee's views. ${ }^{34}$ Second, the state had to compensate HM for the costs of filing the communication. ${ }^{35}$ Third, Sweden was obligated to take steps to prevent similar violations in the future, which included ensuring that its legislation, and the application thereof by its courts were consistent with its obligations in terms of the Convention. ${ }^{36}$ Sweden further had to report to the Committee within six months on any action taken to implement the Committee's findings ${ }^{37}$ and had to publish and disseminate the Committee's findings. ${ }^{38}$

\section{ImplicAtions For SOUth AfricA}

\section{(a) Introduction}

Under international human rights law, states have the obligation to respect, protect and fulfil human rights. ${ }^{39}$ The obligation to fulfil human rights is the state's obligation to take legislative, administrative, judicial and other measures (such as resource allocation) that are necessary to ensure that the rights are implemented to the greatest extent possible. ${ }^{40}$ Here attention should also be given to the prevention of human rights violations - legislation and other measures should be in place to prohibit actions which could interfere with the fulfilment of human rights. In South Africa, equality legislation is an example of such action by the state to fulfil and protect human rights. ${ }^{41}$ The obligation to protect human rights requires the state to avoid human rights violations by private persons. ${ }^{42}$

Human rights that are codified in international treaties, such as the CRPD, are to be protected first and foremost by the relevant national legal protection institutions. International courts and monitoring bodies are appealed to only

33 The Committee is not empowered to exercise any other sanctions. See part IV below.

$34 H M v$ Sweden (note 8 above) para 9.1.

35 Ibid.

36 Ibid para 9.2.

37 Ibid para 10.

38 Ibid.

39 M Nowak Introducing the International Human Rights Regime (2003) 49. Jackie Dugard argues that the observation of human rights is an international legal norm (see J Dugard 'Public International Law' in M Chaskalson et al (eds) Constitutional Law of South Africa (1996, 3 rev 1999) 13-7).

40 Nowak ibid 49.

41 Promotion of Equality and Prevention of Unfair Discrimination Act 4 of 2000. See below.

42 Nowak (note 39 above) 49. Manfred Nowak argues that states usually take measures to protect the rights of its citizens. In the case of domestic violence legislation, the state is taking legislative measures to protect the rights of its citizens, and to ensure that a violation does not happen. Also, historically, the aim of human rights protection was protection against private abuses - such as freedom of religion is against the monopoly of a universal church. Therefore, at national level, such human rights violations are always enforceable against private persons and state bodies. An example in international law where the same situation exists is international criminal law: art 3 of the four Geneva Conventions of 1949 and the second additional protocol of 1977 are binding also on non-state combatants (at 53). 
as a last resort in the event that the national legal process is unsuccessful or the treaties are interpreted in conflicting ways. ${ }^{43}$ Many treaties require that domestic remedies be exhausted before an appeal may be made to an international body. The international human rights system, therefore, not only coexists with the national system, but the national system is usually the first level of defence against human rights abuses.

As stated above, South Africa signed the CRPD and the Optional Protocol on 30 March 2007 and ratified both instruments on 30 November 2007. In terms of s 231 of the Constitution of the Republic of South Africa, 1996, the negotiation and signing of international agreements (such as treaties) are the responsibility of the executive. In the case of the CRPD and the Optional Protocol, the former Minister of Foreign Affairs (currently the Minister of International Relations and Cooperation), signed the Convention on behalf of South Africa. ${ }^{44}$

South Africa belongs to the dualist tradition regarding the incorporation of treaties into its national law. ${ }^{45}$ This is determined by s 231(2) of the Constitution which states that international agreements bind the Republic only after they have been approved by resolution in both houses of Parliament (the National Assembly and the National Council of Provinces), unless they are of the type of agreement referred to in s 231(3). International agreements that require ratification thus require an act in the form of a resolution by the legislature to transform them into national or municipal law. Therefore, in order to incorporate the CRPD into its national law, South Africa had to pass enabling legislation incorporating the CRPD and the Optional Protocol into its legal system.

This was not done in the case of the CRPD. The initial enthusiasm displayed by South Africa in signing and ratifying the two treaties in 2007 was not followed through by an adequate incorporation of the CRPD into South Africa's legal framework. ${ }^{46}$ Although the right of persons with disabilities to equality is guaranteed in s 9 of the Constitution, and although both the Promotion of Equality and the Prevention of Unfair Discrimination Act 4 of 2000 (PEPUDA) and the Employment Equity Act 55 of 1998 protect persons with disabilities against unfair discrimination, there is no disability-specific legislation in place in South Africa. ${ }^{47}$ Therefore, one has to agree with the

43 Nowak ibid 38.

44 'Convention on Rights of Persons with Disabilities: Briefing by the Office on Status of Disabled Persons \& Department of Foreign Affairs' (2007) <http://www.pmg.org.za/minutes/20070524convention-rights-persons-disabilities-briefing-office-status-disabled-persons-depa $>$.

45 'Dualist' states may not incorporate or transform international human rights treaties into national law except through an express order from the national legislator. This is in contrast with monist states who consider international and national law to be one system of law - in this regard, see J Dugard International Law A South African Perspective 4 ed (2011) 43-5.

46 HRC Submission to the Portfolio Committee and Select Committee on Women, Children and People with Disabilities Implementation of the Convention on the Rights of Persons with Disabilities (CRPD) (25 July 2012) 3. 
view of the Human Rights Commission (HRC) that this weakens the effect of the CRPD in South Africa. ${ }^{48}$

\section{(b) Implementation of the CRPD in South Africa}

When becoming a party to an international or regional human rights treaty, State Parties agree to be bound by the provisions of the treaty. In the case of the CRPD and the Optional Protocol, South Africa is subject to the monitoring of its treaty obligations by the CRPD Committee. Such monitoring of its obligations consists of, inter alia, the receiving and consideration by the CRPD Committee of periodic reports from State Parties. As well, according to art 33 of the CRPD, states must designate national focal points for the implementation of the CRPD, coordination mechanisms, implementation mechanisms, and legal and administrative frameworks to promote and monitor its implementation, and finally states must ensure the participation of civil society. ${ }^{49}$ The CRPD further requires that each State Party assists the CRPD Committee in the execution of its mandate..$^{50}$

In terms of the CRPD, each Sate Party has to submit a comprehensive report to the CPRD Committee within two years of the CRPD Convention coming into effect, via the United Nations secretary-general. ${ }^{51}$ This report must set out the progress that has been made in the implementation of the CRPD in relation to standards contained in the CRPD. ${ }^{52}$ Each report must be made available to the public for comment through suggestions and recommendations and the state is to take steps to facilitate such public participation. ${ }^{53}$ After this initial report, each state has to submit follow-up reports every four years (or whenever the Committee requires it to do so). ${ }^{54}$ Problems related to the implementation of the Convention may also be highlighted in the report. ${ }^{55}$

South Africa has thus far failed to submit its first report to the CRPD Committee, thus failing in this commitment to the CRPD. This report was

48 Ibid 3.

49 In terms of art 33(1) of the CRPD, the State Party 'shall designate one or more focal points within government for matters relating to the implementation of the CRPD, and shall give due consideration to the establishment or designation of a coordination mechanism with government to facilitate related action in different sectors and levels'. It thus appears as if provision is made for the South African HRC to fulfil this role. Moreover, s 14(1)(b)(vi) of the South African Human Rights Commission Bill of 2013 is possibly applicable to the monitoring and implementation of the CRPD: sub-art (vi) of the Bill determines that the HRC '[m]ust monitor the implementation of, and compliance with, international and regional conventions and treaties, international and regional covenants and international and regional charters relating to the objects of the Commission'. Consequently, apart from its powers in terms of s 184 of the Constitution, in terms of the Bill the $\mathrm{HRC}$ has the function of monitoring the implementation of conventions such as the CRPD. Specifically, the HRC is compelled to hand in reports to the National Assembly on conventions relating to the SAHRC's objects.

50 Its mandate is set out in art 34 of the CRPD.

51 See art 35: 'Each State Party shall submit to the Committee, through the Secretary-General of the United Nations, a comprehensive report on measures taken to give effect to its obligations ...'.

52 CRPD art 35(1)

53 Ibid art 35(4).

54 Ibid art 35(2).

55 Ibid. 
due in May 2010. On 26 November 2012, South Africa's Draft First Country Report to the UN on the Implementation of the Convention on the Rights of Persons with Disabilities was published for public comment by the Department of Women, Children and People with Disabilities. ${ }^{56}$ The due date for comments on the Draft Report was 25 January 2013. ${ }^{57}$ As of 30 June 2013, the final Country Report had not yet been submitted to the CRPD Committee.

\section{(c) Implications of the CRPD Committee's findings in HMv Sweden for South Africa}

Two aspects of the CRPD Committee's findings deserve mention in relation to disability law in South Africa: the finding that laws applied in a neutral manner may have a discriminatory effect; and its finding that Sweden had failed in its duties in terms of the Convention to allow for 'reasonable accommodation'.

\section{(i) Reasonable accommodation}

In HMv Sweden, the CRPD Committee recognised that a law which is applied in a neutral manner may have a discriminatory effect on persons with disabilities when their particular circumstances are not taken into consideration. Such a need to consider the particular circumstances of persons with disabilities is referred to by the CRPD Committee as 'reasonable accommodation'. 'Reasonable accommodation' is defined in art 2 of the CRPD as 'necessary and appropriate modification and adjustments not imposing a disproportionate or undue burden, where needed in a particular case, to ensure to persons with disabilities the enjoyment or exercise on an equal basis with others of all human rights and fundamental freedoms'. Failure to make reasonable accommodation is regarded by the CRPD as a form of discrimination. As is shown in HMv Sweden, a denial of reasonable accommodation may be a separate and distinct basis upon which to base a claim of discrimination under the CRPD. ${ }^{59}$ Measures regarding reasonable accommodation are to be found in arts 2, 5, 14, 24 and 27 of the Convention.

South Africa's legislation has a reference to the concept of reasonable accommodation in PEPUDA. In terms of s 9 of PEPUDA, when reasonably accommodating persons with disabilities, social transformation is achieved by eliminating social and economic inequalities, especially systemic inequalities. A refusal to accommodate persons with disabilities results in their exclusion from mainstream society.

Department of Women, Children and People with Disabilities Draft First Country Report to the UN on the Implementation of the Convention on the Rights of Persons with Disabilities was published for Public Comment by the Department of Women, Children and People with Disabilities (2012).

57 Ibid 2.

58 See generally JE Lord \& R Brown 'The Role of Reasonable Accommodation In Securing Substantive Equality for Persons with Disabilities: The UN Convention on the Rights of Persons with Disabilities' (2010) <SSRN: http://ssrn.com/abstract=1618903> or $<$ http://dx.doi. org/10.2139/ssrn.1618903>. 
Although MEC for Education Kwazulu-Natal v Pillay ${ }^{60}$ did not deal with disability, it remains relevant for persons with disabilities in relation to the principle of reasonable accommodation. The Constitutional Court refers as follows to the principle: $:^{61}$

(T)he Equality Act specifically requires that reasonable accommodation be made for people with disabilities. Disabled people are often unable to access or participate in public or private life because the means to do so are designed for able-bodied people. The result is that disabled people can, without any positive action, easily be pushed to the margins of society.

In the above-mentioned case the Constitutional Court determines that fairness in some instances requires reasonable accommodation. In this regard two factors should be taken into account: $:^{62}$

First, reasonable accommodation is most appropriate where, as in this case, discrimination arises from a rule or practice that is neutral on its face and is designed to serve a valuable purpose, but which nevertheless has a marginalising effect on certain portions of society. Second, the principle is particularly appropriate in specific localised contexts, such as an individual workplace or school, where a reasonable balance between conflicting interests may more easily be struck. Even where fairness requires a reasonable accommodation, the other factors listed in section 14 will always remain relevant.

A number of cases have been brought relating to 'reasonable accommodation' in terms of s 9 of PEPUDA. In February 2004, a paraplegic practicing attorney won a case in the Equality Court in Germiston, forcing the departments of Justice and Public Works to reasonably accommodate her needs as a wheelchair user to gain access to court buildings. ${ }^{63}$ In 2010, the Equality Court in Witbank ordered a private school to accommodate a learner with a physical disability. ${ }^{64}$

The concept of 'reasonable accommodation' is also defined in s 1 of the Employment Equity Act 55 of 1998 as 'any medication of adjustment to a job or to the working environment that will enable a person from a designated group to have access to or participate or advance in employment'. In addition, a Code of Good Practice on the Employment of Persons with Disabilities sets standards for the employment of persons with disabilities. ${ }^{65}$

6020081 SA 474 (CC), 20082 BCLR.

61 Ibid para 74.

62 Ibid para 78

63 Esthe Muller v Minister of Justice \& Minister of Public Works Case No 01/2003 Equality Court, Germiston. Also see WH Bosch $v$ The Minister of Safety and Security \& Minister of Public Works Case No 24/2005 9 Equality Court, Port Elizabeth.

64 Lettie Hazel Oortman v St Thomas Aquinas Private School Case No 1/2010 Equality Court, Witbank.

65 Department of Labour Code of Good Practice on Key Aspects on the Employment of Persons with Disabilities(19August2002)<http://www.labour.gov.za/DOL/legislation/codes-of-good-practise/ employment-equity/code-of-good-practice-on-disability-in-the-workplace>. 
The Labour Relations Act 66 of 1995 protects employees with disabilities from unfair dismissals. ${ }^{66}$ Section 187(1)(f) determines that an employee's dismissal will be automatically unfair if the employer acted contrary to $\mathrm{s} 5$, or if the employer discriminated directly or indirectly against the employee on any arbitrary ground, including disability. ${ }^{67}$ Therefore, persons with disabilities are protected against discrimination or any other similar unfair treatment when applying for a position, during the subsistence of the employment contract or at termination of the contract. ${ }^{68}$

This principle was confirmed in Standard Bank of SA v Commission for Conciliation, Mediation \& Arbitration ${ }^{69}$ when the court, finding that an employee left disabled after a motor-vehicle accident had to be reasonably accommodated at her place of employment, commented as follows about the marginalisation of people living with disabilities:

\begin{abstract}
Many employers tend to exclude and marginalise employees with disabilities not merely because the disability impairs the employee's suitability for employment, but also because the employer regards the disability as an abnormality or flaw. When the attitude that disability is the problem of the disabled individual, not society, that the workplace is hazardous for disabled people and that they need to be looked after combines with paternalism, charitableness, ignorance and misinformation about disabilities, the result is that more disabled people are dismissed than accommodated. Some employers may find it more convenient to budget for a disability dismissal than to attempt to accommodate an employee. ${ }^{70}$
\end{abstract}

As is pointed out by Janet Lord and Rebecca Brown, the duty to provide reasonable accommodation in the CRPD extends to a broad array of social actors. $^{71}$ In South Africa, this is reflected in PEPUDA and the Employment Equity Act 55 of 1998 (EEA) as not only the state, but also employers, educational institutions and health-care providers, to name but a few, will have to 'adjust policies, practices and premises that impede the inclusion and participation of persons with disabilities, ${ }^{72}$ South Africa, consequently, will have to take positive measures to 'reasonably accommodate' or address the needs of persons with disabilities. These measures will have to ensure

66 See generally Abels and Dialogue Group (Pty) Ltd (2009) 30 ILJ 2167 (CCMA); Gebhardt v Education Labour Relations Council (2013) 1 BLLR 28 (LC); F Bhabha 'Disability Equality Rights in South Africa: Concepts, Interpretation and the Transformation Imperative' (2009) 25 SAJHR 218; C Ngwena 'Deconstructing the Definition of "Disability" under the Employment Equity Act: Legal Deconstruction' (2007) 23 SAJHR 116.

67 Van Rensburg v Northern Cape Provincial Administration 1997 ILJ 1421; Hoffmann v SA Airways 2000 ILJ 891 (W), 2000 IJL 2357 (CC); N v Minister of Defence 2000 ILJ 999 (ACN); IMATU v City of Cape Town 2005 ILJ 1404 (LC).

68 F van Jaarsveld \& S van Eck Kompendium van Arbeidsreg (2003) 168.

69 (2008) 29 ILJ 1239 (LC), 20084 BLLR 368.

70 Ibid 368-9. In this case the court further found that 'in the case of incapacity employees, dismissal is fair where the obligation to accommodate the employee imposes unreasonable hardship on the employer' and that '[ $\mathrm{h}]$ ardship in this context means more than mere inconvenience'. Also see van Jaarsveld \& van Eck (note 68 above) 168; Association of Professional Teachers $v$ Minister of Education 1995 ILJ 1048 (IC); Woolworths Pty Ltd v Whitehead 2000 ILJ 571 (LAC); Hoffmann v SA Airways 2000 ILJ 891 (W); Mahlanyana v Cadbury (Pty) Ltd 2000 ILJ 2274 (LC); and Ackerman v United Cricket Board of SA 2004 IJL 353 (KVBA).

71 Lord \& Brown (note 58 above) 279.

72 Ibid. 
their equal right to work, education, health and other social goods. The cases discussed above indicate that South Africa still has a long way to go in this regard. In each instance it is shown that, despite legislative imperatives to the contrary, the employers had failed in practice to reasonably accommodate their disabled employees: either by neglecting to adapt the workplace to accommodate a woman left disabled after a motor vehicle accident, or by failing to facilitate access to court buildings for a wheelchair-bound paraplegic practicing attorney.

\section{(ii) 'Indirect' discrimination and substantive equality}

The CRPD Committee observed in HMv Sweden that a law which is applied in a neutral manner may have a discriminatory effect when an individual's particular circumstances are not considered. It stated that 'the right not to be discriminated against in the enjoyment of the rights guaranteed under the Convention can be violated when States, without objective and reasonable justification, fail to treat differently persons whose situations are significantly different'. This is linked closely to the idea that reasonable accommodation should be made to provide for the particular needs of persons with disabilities.

South African law protects against indirect discrimination in the Constitution, PEPUDA and in the EEA. For example, the definition of 'discrimination' in s 1 of PEPUDA provides for substantive equality, and outlaws indirect discrimination: 'any act or omission, including a policy, law, rule, practice, condition or situation which directly or indirectly - (a) imposes burdens, obligations or disadvantage on; or (b) withholds benefits, opportunities or advantages from any person on one or more of the prohibited grounds'. Substantive equality, therefore, takes the circumstances of people with disabilities into account and insists upon equality of outcomes. Substantive equality is articulated as follows in a different context by the Constitutional Court in Bhe v Magistrate, Khayelitsha:

Not only is the achievement of equality one of the founding values of the Constitution, section 9 of the Constitution also guarantees the achievement of substantive equality to ensure that the opportunity to enjoy the benefits of an egalitarian and non-sexist society is available to all including those who have been subjected to unfair discrimination in the past. ${ }^{73}$

As indicated above, in the case of people with disabilities, the achievement of substantive equality means that the physical and social environment must be adjusted to accommodate them, so ensuring equality of outcomes. ${ }^{74}$ In other words, people with disabilities must be fully accommodated by society. Accommodation means that the social environment must be made accessible for people with disabilities by removing both environmental and attitudinal barriers.

74 I Grobbelaar-du Plessis \& S van Eck 'Protection of Disabled Employees in South Africa: An Analysis of the Constitution and Labour Legislation' in I Grobbelaar-du Plessis \& TP van Reenen (eds) Aspects of Disability Law in Africa (2011) 240. 
Section 9 of PEPUDA, aimed specifically at disabled persons, strengthens the prohibition against unfair direct and indirect discrimination:

Subject to section 6, no person may unfairly discriminate against any person on the ground of disability, including

(a) denying or removing from any person who has a disability, any supporting or enabling facility necessary for their functioning in society;

(b) contravening the code of practice or regulations of the South African Bureau of Standards that govern environmental accessibility;

(c) failing to eliminate obstacles that unfairly limit or restrict persons with disabilities from enjoying equal opportunities or failing to take steps to reasonably accommodate the needs of such persons.

On the face of it, therefore, it appears from the above that the South African legislature has put the necessary measures in place to protect disabled persons against indirect discrimination and to ensure the achievement of substantive equality.

Nevertheless, despite ensuring equality in terms of outcomes in its legislation, there are very few indications that policy and practice in South Africa realise the significance of ensuring that laws are applied to people with disabilities in a process that considers their individual situation and which allows for 'reasonable accommodation'." The court cases mentioned above illustrate the fact that practice in South Africa in many instances continues to violate the rights of people with disabilities, preventing them from achieving substantive equality.

The case of Western Cape Forum for Intellectual Disability v Government of the Republic of South Africa ${ }^{77}$ is a further example of such continued violation. The case concerned the constitutionality of South African state policy and practice for the funding and provision of schools for children who were classified as having 'severe and profound intellectual disabilities' in the Western Cape. As part of the discharge of its constitutional duty to provide basic education, the Western Cape provincial government had established 'special schools' to cater for the needs of children with 'moderate to mild intellectual disabilities', but made no such provision for children classified as having 'severe and profound intellectual disabilities'. The state also differentiated in terms of funding between 'mainstream' schools and 'special schools', leaving 'special schools' far less well off. ${ }^{78}$

In their appraisal of the court's decision in the above-mentioned case, Charles Ngwena and Loot Pretorius succinctly comment:

The policy had the effect of not only depriving a very vulnerable group of children of their fundamental rights to equality and basic education under the Constitution, but also

76 For comparative purposes, see LA Silecchia 'The Convention on the Rights of Persons with Disabilities: Reflections on Four Flaws that Tarnish its Promise' (2013) $30 \mathrm{~J}$ of Contemporary Health Law and Policy 96.

77 (2011) 5 SA 87 (WCC). See C Ngwena \& L Pretorius 'Substantive Equality for Disabled Learners in State Provision of Basic Education: A Commentary on Western Cape Forum for Intellectual Disability v Government of the Republic of South Africa' (2012) 28 SAJHR 81.

78 Western Cape Forum for Intellectual Disability v Government of the Republic of South Africa para 48. 
accentuating their stigmatisation. In not so many words, the policy was tantamount to ontologically and normatively according low moral status to children who are severely or profoundly intellectually disabled. ${ }^{79}$

In other words, the provincial government's policy, by failing to provide for substantive equality:

push[ed] a group of disabled learners further to the margins of society. State policy and practice fell woefully short of recognising children with severe or profound intellectual disabilities as a social group that requires both cultural and redistributive economic justice. ${ }^{80}$

In this case, although the appropriate legislative safeguards were in place which provided for substantive equality and reasonable accommodation, ${ }^{81}$ the provincial government's policy and practice took no account of these safeguards. It is unclear whether this was a result of a lack of awareness on the part of the provincial government of the extent of its duties regarding ensuring the substantive equality of children with disabilities, or rather a misinterpretation of what it means to reasonably accommodate children with disabilities. The consequence was that, instead of putting measures in place to ensure their substantive equality, the provincial government furthered these disabled learners' marginalisation.

In this regard, then, $H M v$ Sweden shows the dangers of situations where legal rules are applied in a neutral manner, without making provision for equality in terms of outcomes, producing a disproportionate and discriminatory effect. ${ }^{82}$ In $H M v$ Sweden, the CRPD Committee found that a state's failure to treat a person with disabilities differently when the situation warrants it, amounts to discrimination as the definition of discrimination on the basis of disability in terms of the Convention includes 'denial of reasonable accommodation'. South African courts could use the CRPD Committee's finding to ensure the achievement of substantive equality for persons with disabilities in South Africa.

\section{CONCLUSION}

The CRPD is not only the first legally-binding human rights instrument dedicated exclusively to the rights of persons with disabilities, but in situating the requirement that reasonable accommodation be accorded to persons with disabilities in the realisation of their rights, it situates disability rights within a progressive substantive equality rights framework. ${ }^{83}$ The CRPD, therefore, develops a particular field of application of existing rights in a

81 See the discussion in part IV c)(i) above.

82 In this regard, see also A Lawson 'The United Nations Convention in the Rights of Persons with Disabilities: New Era or False Dawn?’ (2007) 34 Syracuse J of Int \& Comparative Law 563; S Wildeman 'Protecting Rights and Building Capacities: Challenges to Global Mental Health Policy in Light of the Convention on the Rights of Persons with Disabilities' (2013) 41 J of Law, Medicine \& Ethics 48.

83 Lord \& Brown (note 58 above) 306. 
way that is specifically relevant to the needs and circumstances of persons with disabilities, affording them optimal enjoyment of those rights. As such, the CRPD supplements existing international human rights treaties, making the rights contained in these treaties specifically applicable to the situation of people with disabilities. The CRPD is clear on the fact that all existing human rights also apply to persons with disabilities. In this regard the general principles emphasised in art 3 of the CRPD (respect for the inherent dignity and individual autonomy of persons with disabilities; their freedom to make their own choices independently; the prohibition on discrimination against persons with disabilities; equal opportunities for persons with disabilities; and equality between men and women) should be incorporated into a reading of rights already existing in international human rights treaties.

It is of particular importance that the CRPD does not, in the first instance, regard disability as a deviation or a pathological condition, but rather as part of human diversity. This reflects a revolutionary view about persons with disabilities and confirms the notion that disability should fall within the social model $^{84}$ of disability, with special emphasis on the human rights perspective on disability.

The Preamble to the UN's 'Handbook for Parliamentarians on the Convention on the Rights of Persons with Disabilities and its Optional Protocol, ${ }^{85}$ comments as follows regarding the CRPD:

The Convention is long overdue. It is over 25 years since the 1981 International Year of Disabled Persons brought global attention to the issues affecting persons with disabilities. In the intervening years, many societies have moved away from considering persons with disabilities as objects of charity and pity, by acknowledging that society itself is disabling. The Convention embodies this attitudinal change, and is a major step towards altering the perception of disability and ensuring that societies recognize that all people must have the opportunity to reach their full potential.

$H M v$ Sweden exemplifies the way in which society, itself, may be disabling. In its refusal to allow the reasonable accommodation of a disabled person's needs, the Swedish authorities contributed - even potentially entrenched - HM's disability. It is to be hoped that the CRPD Committee's views, in upholding HM's rights on an equal basis to that of able-bodied persons, will go some way towards changing society's views on disability, fulfilling the promise of the CRPD to grant all people the opportunity to reach their full potential.

While the medical model of disability is aimed at a search for medical solutions to facilitate the disabled person's integration into society, the social model of disability focuses not on the disabled individual, but on the physical and social environment. According to this model, a person with a disability is not necessarily disabled because of a condition inherent in the individual concerned, but because of the physical and social arrangement of the environment. The emphasis of this model is therefore on an understanding of disability as something, which is brought about or caused by environmental and social barriers. See I Grobbelaar-du Plessis \& TP van Reenen 'Introduction to Aspects of Disability Law in Africa' in Grobbelaar-du Plessis \& van Reenen (note 74 above) xxiii-vii.

85 UN Exclusion to Equality - Realizing the Rights of Persons with Disabilities (2007) <http:// www.un.org/disabilities/default.asp?id=212>. 